\title{
How and Why Bilingualism is Being Promoted by Omani Parents and How Bilingualism is Impacting their Children's Everyday Lives
}

\author{
Ali Kemal Tekin* \\ College of Education, Sultan Qaboos University \\ School of Education, University of South Australia \\ Laila Al-Salmi \\ College of Education, \\ Sultan Qaboos University
}

\begin{abstract}
Expectations of the globalized society and changes in family dynamics have a significant impact on children's development as supported by the Ecological Systems Theory. Parents have become more interested in raising their children as bilinguals as it has become an inescapable trend, particularly in certain regions of the world. Children of the Gulf are also affected by this bilingualism movement. Therefore, this study attempts to understand the bilingual children of the Gulf in the case of Oman by addressing three major research questions: (1) "why and how bilingualism is being promoted by parents", (2) "how bilingualism is impacting on the intergenerational relationships in the Gulf family", and (3) "how bilingualism is impacting Gulf children's everyday lives". Participants were ten parents whose children were enrolled at a bilingual education program at Sultan Qaboos University (SQU). The data was collected through interviews and the case study approach was deployed in data analysis. Findings were revealed about why and how parents promote bilingualism, to what extent the bilingualism impact on the intergenerational relations, and the effects of bilingualism on children's everyday lives. Implications and recommendations for policy, practice, and research are offered.
\end{abstract}

Keywords: bilingual education; early childhood bilingualism; early childhood education; language development; intergenerational relations.

* Corresponding author: Ali Kemal Tekin, Email: tekn@squ.edu.om; Tel.: +96893284364 


\section{Introduction}

\subsection{Background \& Context}

In today's world, parental roles have been extended to involvement in all aspects of their children's education and development, from decision making with respect to the curriculum of educational programs, to language development. In contemporary early childhood education settings, parents are eager to be more involved in their young children's educational lives and are required to do so regardless of traditionally held gender role stereotypes. For example, schools ask fathers to be more involved in their young children's education and development. As Ancell, Bruns, and Chiyito (2018) claimed, it is beyond their traditional role and responsibilities of financial support and protection. The new generation of parents has welcomed these expectations and is showing more interest in extending their dynamic role in their children's education due to societal development. In this regard, many parents are highly motivated to become involved in their children's education from volunteering to learning at home. Their major motivation is to ensure that their children possess what it takes for their globalized future life and become better functioning individuals in modern society. This transformation of the parental roles and transition in education-concentrated active parenting is also echoed in the Gulf context in general and Omani context, in particular.

Oman is located in the Southeastern Arabian Peninsula and a member of the Gulf Cooperation Council (GCC). Its population is 4,690,283 and among this population, 56.40 percent are Omani and 43.60 percent are expatriates (National Center for Statistics and Information, 2019). Its population is predominantly Muslim. The country's nominal GDP per capita was 19,310 USD in 2014 and it was 40,122 USD based on purchasing power parity (PPP) (World Bank, 2019) and its main revenues are from natural gas and oil. Today, there are 1,149 public schools in the country, educating a student population of 603,797 (Ministry of Education, 2019).

In addition to the efforts of the Omani Government to enhance its education system to meet the United Nations Sustainable Development Goals 4.2 by 2030 with respect to the quality of early education, there are also economic, social, and cultural transformations demanding changes from the educational sector. Bilingual education is one of the foremost desired components of the new demands from the educational institutions. As stated by Rose and Tudge (2013), all dynamic concepts and applications, particularly in the social life, are subject to change within the chronosystem through an interaction with the environmental elements and social dimensions both at the micro and macro levels. Therefore, children's education is also expected to evolve to accommodate new programs with contemporary applications. In line with this notion of change, the world has been going through inescapable globalization that is almost dictating to people everywhere to learn more languages, especially English. Consistent with these developments, the country's strategic planVision 2040- English is perceived by the government and society as an overarching dimension of growth. As a result, the teaching and learning of 
English and bilingualism will continue to be a major concern in Oman and the Gulf in the coming decades.

Omani parents, empowered by the new child law are not immune to these developments. Consequently, they have started to demand educational systems that would create bilingual individuals who would easily integrate with the global community. This phenomenon has been closely observed especially by the private educational entrepreneurship in the country, leading them to found many bilingual institutions proposing education programs in two languages, Arabic (L1) and English (L2), as early as the preschool years as many new early bilingual education programs have been introduced. In compliance with bilingualism prevalent in the society and bilingual programs in education, the national university of Oman, Sultan Qaboos University (SQU), took the initiative to establish a Child Care Center (CCC) in 2007 on-campus to set a model for early bilingual education in the country. In order to achieve this goal, the Center provides a 50/50 balance between two languages. This aspect of the CCC's program attracts many parents to enroll their children in the program.

The research about early bilingualism and early bilingual education is severely limited in the Gulf context. To the authors' knowledge, there has been no study conducted in the Gulf context investigating specifically the parents' beliefs particularly about how and why they support early bilingualism, how the bilingualism of their children is interacting with family dynamics such as relationships, and how bilingualism is impacting their children's everyday lives. These topics should be investigated in order to fully understand the bilingual movement and phenomenon of bilingual children of the Gulf. This information could be retrieved best from the parents as they are the most reliable source of information by being primary caregivers of children, first educators of their children, and main decision-makers of their children's formal and informal educations who are also expected to be involved in their children's learning and practicing process both as observant and active participants. Hence, the scope of this study is to explore how and why bilingualism is being promoted by Omani parents and how bilingualism is impacting their children's everyday lives.

\subsection{Literature Review}

Early bilingualism is supported by the "Critical Period Hypothesis" (CPH), which claims learning a second language is easier, more efficient, and successful in early childhood years essentially because it is seen as a peak time for learning more than one language. Children at an early age have better capacity and competency to learn a new language than others (Peets, Yim, \& Bialystok, 2019). It also makes children faster and more efficient foreign language learners as they learn it at the same time with their L1 because the basic aspects of language acquisition, such as acquiring the syntactic knowledge, are similar whether learning one or more languages at a time as asserted by Werker (2012). Hence, early bilingualism and bilingual education should not be a source of concern.

There are quite a number of studies (e.g., Weber, Johnson, Riccio, \& Liew, 2016) in the literature that has focused on the benefits of bilingualism and bilingual 
education. These benefits were found to exist in different domains of childhood and later periods of life such as their language development. For example, Larson-Hall, Weber, Johnshon, Riccio, and Liew (2008) conducted a study with 61 young children and found that even minimal exposure to an instructed foreign language had a perceivable positive impact on their language development, including the phonetic aspect of language knowledge. Also, research evidence shows that L2 acquisition in early childhood does not have any undesirable influence on learning L1, or other adverse effects on a child's L1 learning and development (Dastgahian \& Rostami, 2013). Instead, learning two languages simultaneously has positive impacts on the child's acquisition of each language's linguistic aspects (Yeung \& Chan, 2012). For instance, the early acquisition of a foreign language is claimed to have positive effects on reading, writing, and spelling (Midgette \& Philippakos, 2016). In line with these findings, a review study documented that bilingual children enjoy higher levels of metalinguistic awareness and competence than their monolingual peers (Barack \& Bialystok, 2011). They also had better English skills and better foreign accents (Kartushina \& Martin, 2019).

Similarly, research evidence indicates positive results of early bilingualism particularly on the cognitive development of young children (Poulin-Dubois, Blaye, Coutya, \& Bialystok, 2011). For instance, it is worth mentioning that the research was conducted through a meta-analysis of 63 studies that examined the cognitive effects of bilingualism for children, and the results showed that early bilingual experience produces cognitive advantages for children in the areas of working memory, attention control, metalinguistic awareness, and abstract and symbolic representation (Adesope, Lavin, Thompson, \& Ungerleider, 2010). More to the point, further research results showed that early bilingualism is associated with better results for planning and decision-making skills by bilingual children compared to monolingual peers (Bialystok, Craik, Green, \& Gollan, 2009). These cognitive benefits of early bilingualism extend across the life span (Bialystok, Abutalebi, Bak, Burke, \& Kroll, 2016). In addition, the same topic was investigated in a Korean-English context with 56 four-year-olds and it was found that bilingual children had a more operational network of executive controls for conflict resolution, better speed in attention processing and problem- than monolingual children (Yang, Yang, \& Yang, 2011). Moreover, another study was carried out with bilingual and monolingual children in a Russian-Hebrew context and to compare certain cognitive skills (Leikin \& Tovli, 2014). The results showed that balanced bilingualism is associated with the development of creativity in children's problem-solving skills. These findings were consistent with a previous study conducted in a similar context, the results of which indicated that early bilingualism had a positive impact on children's general and mathematical creativity (Daubert \& Ramani, 2019).

Furthermore, there are research studies that have documented the positive effects of bilingualism on children's social development. For example, a study was conducted by Zang and Yan (2012) with 128 Chinese kindergartners and it was found that early bilingual education had a positive impact on young children's sociopragmatic and communication skills. Likewise, another study 
done with 83 Turkish children reported positive impacts of early starters of foreign language learners' attitudes towards English compared to late starters (Cepik \& Sarandi, 2012). These findings were supported by other investigators who concluded that bilingualism improves individuals' social relations in a diverse environment by freeing them from different decision biases that might stem from heuristics and affective processes (Keysar, Hayakawa, \& An, 2012).

\section{Materials and Methods}

Qualitative inquiry methods were recruited in this research since it is believed that qualitative methods such as interviewing participants are more suitable to gather in-depth information and rich data and provide detailed insights of participants' about a specific matter (Merriam \& Tisdell, 2016). Particularly, the case study approach was adopted and employed in this study since it aims to gather in-depth and rich information about the aforementioned topics of bilingualism from a specific entity, the CCC at SQU. This is a case study analyzing the experience of bilingual education and raising young bilingual children within a real-life, contemporary context or setting (Crowe et al., 2011). Further, the case study method also features a bounded system (Creswell, 2016), which in this case is the time period from 2018 specifically at the CCC.

As the current study employed the case study approach, the purposeful sampling method was recruited to gather more concrete, solid, and detailed data and information on the target group. The participants of the study were parents with kindergarten children enrolled at the bilingual program of CCC at SQU. While 32 students were registered at the CCC, only the parents of 10 (31 percent) agreed to participate in the research study-the rest 22 (69 percent) did not respond. The participation was on a voluntary basis. All participants were Omani nationals.

Two tools were used to collect data in the present study: first, a demographic survey designed to gather detailed data about participants' age, gender, marital status, and employment status; and a "Parental Perspectives Interview" instrument which was recruited during the interviews with parents. This tool was designed to obtain information on the overarching dimensions of early bilingualism from the perspectives of parents. It consisted of three major questions: (1) Why and how do you promote bilingualism for your child? (2) How is bilingualism impacting on the interpersonal relationships in your family? and (3) How is bilingualism impacting your child's everyday life? These questions were developed by the authors to elicit data that could be used to address the research questions of this study.

Through the communication with the CCC administration, the researcher discussed the objectives, scopes, and the steps of the study, and asked their assistance in contacting the potential participants whose children were enrolled in the bilingual kindergarten program. After securing the initial consent from the CCC administration, the informed consent letters were sent out to the parents along with the time schedule for the interviews. 
Upon receiving parents' responses, participants were scheduled for and participated in interviews and completed the demographic survey. Ten parents were interviewed at CCC and on average the interview sessions lasted between 30 to 50 minutes, though there was no set time limit for the interview sessions. For verification, the participants were asked again to clarify responses and ensure they had been understood correctly as a triangulation procedure following the interviews to support validity issues as suggested by Creswell (2016). All interviews were conducted in Arabic, transcribed, and then translated into English by a bilingual expert in the field of early childhood education. The back-translation processes of the interview protocols by another expert in the field were also followed to ensure the accuracy of the gathered data.

Once the data collection procedures were completed, the investigator made use of descriptive statistics together with case study procedures to analyze the data. Henceforth, the responses from the participants were initially categorized in accordance with the major themes of the study and in line with the topics and research questions by using the thematic analysis method that enables an inquiry's findings to be reported in a more systemic and organized way. Moreover, the researcher deployed the recursive examination of data through peer review as suggested for verification confirmability (Creswell, 2016). Then, responses were transferred into the narration by the authors. While reporting the study, representative answers of participants were also quoted as suggested to convey the findings of the study in a more organized and clear way and to be able to identify the mentioned statements in rank according to their frequency and prioritize them.

\section{Findings}

\subsection{Why and how do parents promote bilingualism for their children?}

Based on the analysis of the responses to the first part of the first question, why they promote bilingualism for their children, several reasons emerged that was commonly stated by the participants. First, nine of the participating parents stated "communication and integration with the world" as one of the reasons for promoting bilingualism for their children. For instance, Parent 9 stated,

"I promote bilingualism for my child because specifically English is the language of the world and learning it has become a priority in this life. By being bilingual, her communication skills will improve. Wherever we travel inside or outside Oman, English is the means for communication. Therefore, it is important and should be learned in order to integrate and communicate with others."

Supporting this perspective, Parent 1 said, "Learning a different language helps my child learn about the different cultures and people through the literature and the books written in that language which will essentially help with communicating with and connecting to the world."

Second, among ten parents, eight of them showed "future educational and career opportunities" as one of the reasons for them promoting bilingualism for their children. They see learning English and thus being bilingual individuals 
advantageous in their children's further academic life, in turn, future careers. For example, Parent 6 said,

"I promote bilingualism for my son because he will need English to be admitted by good universities, nowadays all good universities' medium of instruction is English. It is mostly necessary for admission. He will also need it to have good job opportunities in his future."

Third, four of the participants mentioned cognitive advantages as one of the reasons for promoting bilingualism for their children. For instance, Parent 6 said, "Another reason for me to promote my child's bilingual development is that it helps to improve his perception skills. In addition, it contributes to his thinking level and complexity. I think bilingual people develop higher thinking levels." In line with this statement, Parent 3 said,

"I believe bilingualism helps my child's mental growth and development. I promote bilingualism for my child because learning languages can help my child to improve his way of thinking. Languages are not memorizing, rather a mental process that needs higher thinking. It also helps with attention."

Hence, these were the three reasons that the participants of the current study asserted for promoting their children's bilingualism. A few other reasons were mentioned by individual participants such as two parents mentioned bilingualism improving the self-confidence and two others pointed out it helps reading.

Regarding the second part of the question, how they promote bilingualism for their children beyond providing their children with bilingual education, the most common answer was reading books together with their children in both languages. This answer was given by seven participants. Three parents stated that they talk to their children in two languages thinking that they promote their children's bilingual development in this way. For example, Parent 5 stated, "I read storybooks in both languages together with my child, it helps quite a lot to acquire both languages simultaneously. I also try to promote my child's bilingual development by talking to him in both languages." The third common method was using computer games. In addition, two parents stated that they used educational TV shows. One participant stated that she used music. Finally, two parents said that they did nothing specific to promote their children's bilingual development.

\subsection{How is bilingualism impacting interpersonal relationships within the family?}

After reviewing the answers for the second interview question, it was found that six participants observed changes in their communication with their children, which they believed was due to bilingual development. For example, Parent 2 stated, "I have used English with my children since they were very young and right now, they use more English than Arabic even at home and with everyone as a means of communication." Besides, four of these parents mentioned their children's confidence in their relations with them have improved because of bilingualism. For instance, Parent 4 said, 
"I think he has become more confident in his relations with us and others. He also has become calmer and gained more self-control than before. He can express his needs more thoughtfully. I believe these changes are due to bilingual education."

In favor of this statement, Parent 9 said, "Before she learned English, it was hard for my child to express her feelings and needs, but now she has more control over her behavior as she uses more than one language to communicate with others." In addition, three parents reported that they believe their children's interpersonal relations have improved due to bilingual development. For instance, Parent 7 stated,

"I think my child started to feel and act more mature in his relations with us. She also started to look for different ways to express her needs and tries many ways to do that, which shows that she has developed empathy. She does not use crying, for example, to communicate with us."

With regards to a behavioral change in their relations, Parent 4 stated, "What I am more interested in is his behavioral change caused by bilingualism. His behaviors in his relations with us changed a lot after learning English. I think this is because we use English stories and books that have a variety of subjects through reading together we can discuss a lot of subjects and characters, what is good and bad, and how we should behave. There are not many Arabic books providing us this opportunity."

Hence, based on participants' reports, it was found that three major domains of relations were impacted by the bilingualism. These areas were social (e.g. communication), emotional (e.g. confidence), and behavioral (e.g. acting more mature). No negative changes were reported by the parents. Four of the participants stated that they did not observe any impact of bilingualism on their interpersonal relationships with their children. For instance, Parent 10 said, "I have not noticed any difference actually. This might be because I started to teach him both languages since he was very young."

\subsection{How is bilingualism impacting the child's everyday life?}

The third inquiry point of this study was the impact of bilingualism on the child's everyday life from the perspective of their parents. The interview data revealed several findings in this regard. First, among the participants, five parents asserted that bilingualism had impacted their children's everyday life in a way that they have the confidence to socialize and communicate with the world outside the family, especially with the non-Arabs in the country. For example, Parent 1 said,

"My daughter started to like using English, which is a new language for her, not only while communicating with her siblings and family but also when we go shopping or to restaurants, she tries to speak and express her needs with the proper language- Arabic or English- according to the situation." 
In line with that statement, Parent 7 also stated, "She uses English with her peers and at home. I think after she learned English, she has become more confident in socializing with others, thus, she has made more friends. She is more social now and she likes to meet and talk with other people. She also uses English with her housemaid, for example."

A second finding from the interviews was the impact of bilingualism on young children's use of language. Code-switching (i.e. switching the languages deliberately and consciously, that is, an English sentence is followed by an Arabic sentence and vice versa) and code-mixing (i.e. mixing two languages, that is, inserting an English word into an Arabic sentence) among children while communicating in their daily lives was reported by three parents. For instance, Parent 10 said, "He uses English everywhere we go and he likes to do that with his friends as well. But sometimes if he feels that the other person will not understand him he immediately shifts to Arabic."

Third, findings showed that bilingualism might have an impact on the child's literature preferences. Although it was mentioned by only one parent, it is worth noting this aspect of the effect of bilingual education. For example, Parent 2 stated,

"My children use English when texting or writing, they also like to read books in English more than the ones in Arabic. I think they do this because English has become more prevalent in the community than Arabic these days."

On the other hand, two participants reported no impact of bilingualism on their children's everyday lives.

Overall, the current study revealed several important findings that contribute to understanding the case of bilingual children. However, there needs to be further discussion on these findings. Hence, detailed implications are provided in the following section.

\section{Discussion}

The current study was carried out within a bounded system as suggested by the case study approach, therefore, the findings cannot be generalized at a large scale. However, there are still several important implications that can be drawn from the findings of the present study, which also makes it possible to adapt and apply the findings in other contexts with the condition of considering the differences with respect to context such as the variables of participants. Several outcomes of the study should be highlighted.

First, based on the findings of the research, it can easily be claimed that the Omani parents are quite aware of why they promote bilingualism for their young children. Any process or action has more chance to achieve the goal if it is meaningful for the parties. To parents, their children being bilingual means becoming competent in communication and integration with the world, having better opportunities to access higher quality education and career opportunities. These two findings show that bilingualism and particularly learning English has 
become a necessity and a priority in their children's education so they may better function in the future society. Besides these two major findings of why the parents would promote bilingualism for their children, there was an unexpected finding indicating that parents were also aware of the cognitive domains of child development that would improve through bilingualism such as higher thinking skills, attention, and memory. The authors believe that this might be due to the fact that the current study was conducted in a university campus environment and the parents related to university are generally highly educated individuals.

However, parents did not mention learning technology as a reason for promoting bilingualism. The findings also revealed that parents are motivated to become involved in their children's bilingual development. Based on their selfreports, they claimed to promote bilingualism through strategies such as reading together. However, the findings showed that the second-most common method parents use to promote bilingualism was by talking to their children in English. This method is not suggested as an effective way to improve the language knowledge and skills of young children. Parents should speak to their children in their native language, in this case, Arabic, since the parents are the major source for children to gain the greatest language competencies in L1. By talking to them in L2, parents are unwittingly depriving their children of a valuable source for acquiring L1 skills, as advocated by Paradis, Genesee, and Crago (2010). The last technique that parents mentioned they used was computer games. As it is known, computer games are an inescapable phenomenon of modern childhood which has become part of children's daily lives. Thus, it is not surprising that parents would also use them as a tool for promoting bilingualism.

Second, regarding the impact of bilingualism on parents' relationships with their children, the findings showed that the way of their social development (e.g. communication within the family) was affected by the bilingual development of their children. For example, the parents claimed that their children started to use English even at home and within the family. The researcher believes that this change is due to the praise or encouragement from the parents to use L2. In addition, they reported that their children started to have more self-confidence and self-control in their relations than before. It is also interesting that a few parents reported positive behavioral changes in their relations with children due to bilingualism. It is critical to note that a parent mentioned the role of books in L2 had a positive impact on his child's relations, as the child learned about model characters through those stories. It is possible if the quality of the books in L2 is assured. However, it is difficult to ascertain whether there are no other factors influencing a child's change in behavior in addition to the L2-based books.

Third, the findings of the current study showed that parents believe there are certain areas in their children's everyday lives impacted by bilingualism. Communication was the main area affected by bilingualism. The parents reported this could be seen especially in communicating with the outside world, especially with non-Arabs in different contexts such as when shopping, at 
restaurants, and with a housemaid. This phenomenon can be named as "contextual language" since the child prefers L1 or L2 to one another depending on the context. This finding is unique as it contributes to the area of the child's pragmatic language knowledge, which is knowing how to use a particular language in a context (i.e. knowing how and what to say where, when, and to whom). But in this case, this knowledge is extended also to the second language, thus the child starts to develop pragmatic language knowledge skills not only in the primary language but also in the second language. This is an impressive and unique finding. The finding also revealed that the children's everyday communication was affected in a way that they would employ code-mixing and code-switching, which are typical impacts of early bilingualism. Therefore, this finding shows that in terms of certain attributes there are similarities in regards to expected language patterns depicted by children which contribute to the universality of code-mixing and code-switching behaviors among early bilinguals.

\subsection{Suggestions}

Based on the findings of this research, several suggestions are made by the researcher for educators and parents. First, educators must be informed that family dynamics and parental roles have evolved and today's parents are more aware of what is good for their children and also more aware of their expectations from education. Therefore, they should involve parents more through discussion, decision making, and activities that would serve to reap the utmost benefits from bilingualism. They can also provide diverse material for children that they can take and use at home such as educational videos, literacy materials, and software programs and conduct training workshops for parents about how they can help their children's bilingual development at home. Besides, administrators should work on creating training sessions for both teachers and parents.

Second, the study findings imply several suggestions for the parents. Parents should be aware that they should talk in their first language to their children. Parents should train themselves to use different techniques and methods to contribute to their children's bilingualism such as using educational software programs. They should also employ beneficial communication patterns, especially when reading with their children, such as using eye-contact and shared reference, verbal mapping, communication loop, turn-taking, questioning, expanding, and repeating. To be able to apply these methods, they could be provided with seminars and workshops by parents-school-community partnership institutions.

In addition, the findings of this study are found to be positive towards the development of this kind of bilingual movement among the children of the present context. However, it should be noted that English bilingualism has been much understudied in the region and there might be real social tension in this process. For example, the ill-prepared bilingual programs that ignore the contextual and cultural variables such as the relationships and particularly the communication among the family members might encourage children to be 
alienated from their immediate cultural context and defect their relationships with their immediate environment, for instance, with their extended family members such as their grandparents. Hence, hindering nuances and adverse effects, such as negative impacts on interpersonal communication, should also be delineated and these types of programs should be designed in a way to diminish the negative impacts of early bilingualism.

The present study employed the qualitative case study approach within a bounded system. The positive findings of the study may not be generalized but may lead to implications for similar contexts as it was a case study. Further, the characteristics of the participants, for example, all being married or employed indicates a need to do similar studies with participants of different backgrounds. Therefore, there should be more studies on the same topic of bilingualism and its impacts on relations and everyday lives with different methods and research designs. Especially, the reasons behind any change in parent-child or interpersonal relationships should be studied in-depth. The authors propose several questions to be investigated in further research studies. These questions include: (1) Why would children prefer to speak in L2 with their family members? (2) Why would bilingual children have more confidence in their relations with their parents? (3) What are the other reasons for bilingual children's behavioral changes in their relations with their parents?

Furthermore, the current study was conducted with parents based on their selfreports. Therefore, more inquiring techniques such as observation should be used in further research. In addition, the sample size was limited to ten participants. Therefore, there should be more studies with larger sample size and from different areas and diverse populations in order to draw more universal conclusions. Lastly, the context of the present study was limited to Oman. Further studies at a larger scale in other GCC countries would reveal more information about bilingualism and its impacts.

\section{References}

Adesope, O. O., Lavin, T., Thompson, T., \& Ungerleider, C. (2010). A Systematic review and meta-analysis of the cognitive correlates of bilingualism. Review of Educational Research, 80(2), 207-245. doi:10.3102/0034654310368803

Ancell, K. S., Bruns, D. A., \& Chitiyo, J. (2018). The importance of father involvement in early childhood programs. Young Exceptional Children, 21(1), 22-33. doi:10.1177/1096250615621355

Barac, R., \& Bialystok, E. (2011). Cognitive development and bilingual children. Language Teaching, 44(1), 36-54. doi:10.1017/S0261444810000339

Bialystok, E., Craik, F. I. M., Green, D. W., \& Gollan, T. H. (2009). Bilingual minds. Psychological Science in the Public Interest, 10(3), 89-129. doi:10.1177/1529100610387084

Bialystok, E., Abutalebi, J., Bak, T. H., Burke, D. M., \& Kroll, J. F. (2016). Aging in two languages: Implications for public health. Ageing Research Review, 27, 56-60. doi:10.1016/j.arr.2016.03.003

Cepik, S., \& Sarandi, H. (2012). Early and late language start at private schools in Turkey. Education: Science, Theory \& Practice, 12(4), 3199-3209. 
Creswell, J. (2016). Educational research: Planning, conducting, and evaluating, quantitative and qualitative Research (6th ed.). New York: Pearson.

Crowe, S., Cresswell, K., Robertson, A., Huby, G., Avery, A., \& Sheikh, A. (2011). The case study approach. BMC Medical Research Methodology, 11(1), 1-9. doi:10.1186/1471-2288-11-100

Daubert, E. N., \& Ramani, G. B. (2019). Math and memory in bilingual preschoolers: The relations between bilingualism, working memory, and numerical knowledge. Journal of Cognition and Development, 20(3), 314-333. doi:10.1080/15248372.2019.1565536

Dastgahian, E. S., \& Rostami, H. (2013). Early bilingual acquisition: A case study in Iran. International Journal of English Linguistics, 3(6), 97-112. doi:10.5539/ijel.v3n6p97

Kartushina, N., \& Martin, C. D. (2019). Third-language learning affects bilinguals' production in both their native languages: A longitudinal study of dynamic changes in L1, L2, and L3 vowel production. Journal of Phonetics, 77, 1-21. doi:10.1016/j.wocn.2019.100920

Keysar, B., Hayakawa, S. L., \& An, S. G. (2012). The foreign-language effect: Thinking in a foreign tongue reduces decision biases. Psychological Sciences, 23(6), 661-668. doi:10.1177/0956797611432178

Larson-Hall, J. Weber, R. C., Johnson, A., Riccio, C. A., \& Liew, J. (2008). Weighing benefits of studying a foreign language at a younger starting age in a minimal input situation. Second Language Research, 24(1), 35-63. doi:10.1177/0267658307082981

Leikin, M., \& Tovli, E. (2014). Bilingualism and creativity in early childhood. Creativity Research Journal, 26(4), 411-417. doi:10.1080/10400419.2014.961779

Merriam, S. G., \& Tisdell, E. J. (2016). Qualitative research: A guide to design and implementation (4th ed.). San Francisco, CA: John Wiley \& Sons.

Midgette, E., \& Philippakos, Z. A. (2016). Biliteracy, spelling, and writing: A case study. The Language and Literacy Spectrum, 26, 13-30.

Ministry of Education (2019). Educational Indicators. Retrieved from http://home.moe.gov.om/arabic/index.php

National Center for Statistics and Information (2019). Monthly statistical bulletin. Muscat, Oman: Oman Government.

Paradis, J., Genesee, F., \& Crago, M.B. (2010). Dual language development $\mathcal{E}$ disorders: A handbook on bilingualism $\mathcal{E}$ second language learning (2nd ed.). Baltimore, MD: Brookes.

Peets, K. F, Yim, O., \& Bialystok, E. (2019). Language proficiency, reading comprehension and home literacy in bilingual children: The impact of context. International Journal of Bilingual Education and Bilingualism. Advanced online publication. doi:10.1080/13670050.2019.1677551

Poulin-Dubois, D., Blaye, A., Coutya, J., \& Bialystok, E. (2011). The effects of bilingualism on toddlers' executive functioning. Journal of Experimental Child Psychology, 108(3), 567-579. doi:10.1016/j.jecp.2010.10.009

Rosa, E. M., \& Tudge, J. (2013). Urie Bronfenbrenner's theory of human development: Its evolution from ecology to biology. Journal of Family Theory E Review, 5, 243-258. doi:10.1111/jftr.12022

Weber, R. C., Johnson, A., Riccio, C. A., \& Liew, J. (2016). Balanced bilingualism and executive functioning in children. Bilingualism: Language and Cognition, 19(2), 425-431. doi:10.1017/S1366728915000553

Werker, J. (2012). Perceptual foundations of bilingual acquisition in infancy. Annals of The New York Academy of Sciences, 1251, 50-61. doi:10.1111/j.17496632.2012.06484.x 
World Bank (2019). Oman Country Profile. Retrieved from: http:/ / data.worldbank.org/country/oman

Yang, S., Yang, H. J., \& Lust, B. (2011). Early childhood bilingualism leads to advances in executive attention: Dissociating culture and language. Bilingualism: Language and Cognition, 14(3), 412-422. doi:10.1017/S1366728910000611

Yeung, S. S., \& Chan, C. K. (2012). Phonological awareness and oral language proficiency in learning to read English among Chinese kindergarten children in Hong Kong. British Journal of Educational Psychology, 83, 550-568. doi:10.1111/j.2044-8279.2012.02082.x

Zhang, L., \& Yan, R. (2012). Impact of immersion teaching on English sociopragmatic awareness of Chinese kindergarten children: A polite study. International Education, 41(2), 33-45. Retrieved

from http://trace.tennessee.edu/internationaleducation/vol41/iss2/3 